\title{
Parametric analysis of GMAW-P waveforms for the derivation of human exposure values
}

\author{
Daniele Desideri, Alvise Maschio*, Paolo Mattavelli
}

\begin{abstract}
Different pulsed current waveforms, currently used for pulse gas metal arc welding (GMAW-P), have been analyzed from the point of view of human exposure to time-varying magnetic fields. The most common waveforms presented in the literature (i.e. trapezoidal, exponential and combined trapezoidal-exponential) have been considered for a parametric analysis, and the corresponding human exposure indexes related to induced current have been derived on the basis of the EN 50444 and EN 50445 standards. The calculations have been performed in the hypothesis of uniform magnetic flux density perpendicular to a homogeneous round disk. A specific code in MATLAB ${ }^{\circledR}$ has been developed. A parametric analysis has been performed, varying the frequency from $100 \mathrm{~Hz}$ to $400 \mathrm{~Hz}$ and the rise time from $10 \mu$ s to $500 \mu \mathrm{s}$, for all the considered current waveforms. The peak current has been set at $100 \mathrm{~A}$, with a duration of $1 \mathrm{~ms}$, value chosen according to the one droplet per pulse (ODPP) condition. Within the cases considered, as far as the human exposure indexes are concerned, their reduction when the rise time increases was found; moreover, it resulted that the analyzed current waveforms have quite similar impact in the evaluation of these indexes.
\end{abstract}

Keywords GMAW-P, Current waveforms, Human exposure indexes.

\section{Análise paramétrica de formas de onda GMAW-P para a derivação de valores de exposição humana}

Resumo As diferentes formas de onda de corrente pulsadas, usadas atualmente para soldagem por arco elétrico pulsado com proteção gasosa (GMAW-P), foram analisadas do ponto de vista da exposição humana a campos magnéticos variáveis no tempo. As formas de onda mais comuns apresentadas na literatura (trapezoidal, exponencial e trapezoidal-exponencial combinadas) foram consideradas para a análise paramétrica, e os correspondentes indices de exposição humana, relacionados com a corrente induzida, foram derivados com base nos padrões EM 50444 e EM 50445. Os cálculos foram realizados considerando-se uma densidade de fluxo magnético uniforme perpendicular a um disco com superficie homogênea. Um programa dedicado, escrito em linguagem MATLAB ${ }^{\circledR}$ foi desenvolvido. A análise paramétrica foi realizada variando-se a freqüência de $100 \mathrm{~Hz}$ a $400 \mathrm{~Hz}$ e o tempo de subida de $10 \mu \mathrm{s}$ a $500 \mu \mathrm{s}$, para todas as formas de onda. A corrente de pico foi fixada em $100 \mathrm{~A}$, com duração de $1 \mathrm{~ms}$, valor escolhido de acordo com a condição de “uma gota por pulso". Dentre os casos considerados, os índices de exposição humana reduziram à medida que o tempo de subida aumentava, além disso, os resultados mostram que as formas de onda de corrente analisadas possuem impacto similar na avaliação daqueles índices.

Palavras-chave GMAW-P, Formas de onda de corrente, Índices de exposição humana. 


\section{Introduction}

Pulse Gas Metal Arc Welding (GMAW-P) is a commonly used technique for arc welding processes, in particular with aluminium (Praveen et al., 2005; 2006; Subramanian et al., 1999). Several researchers have studied the different aspects of GMAW-P technique, from the point of view of the optimal operation, identifying the most important parameters of the technique. In particular, the waveforms of the output current from the welding equipment have been carefully analyzed, with the aim of obtaining the best performances in the various phases of the welding process.

Human exposure to the magnetic field produced by the output current, flowing in the cables connected to a welding equipment, is an important subject, investigated in the recent years by our group (Desideri and Maschio, 2006; Desideri et al., 2008); moreover it has been object of recent standard issues (European Standards EN 50444, EN 50445). In particular, our group developed a preliminary code in MATLAB ${ }^{\circledR}$ for the analysis of the exposure values due to pulsed current waveforms. Some assumptions were arbitrarily chosen, because at that time there was not a specific standard. The code has been used for a first evaluation, with a simple trapezoidal current waveform, and its operation with a current waveform measured in an experimental set up has been performed successfully (Desideri et al., 2008).

In this paper, the most common GMAW-P current waveforms published in the literature have been investigated and three cases have been considered for the present analysis. A selection of the most significant parameters of the current waveform has been performed and a parametric analysis has been done. For the analyses of the waveforms, a new code, that allows the evaluation of the human exposure according to the european standards EN 50444 and EN 50445 (European..., 2008a; 2008b) has been developed.

The paper reports and discusses the most relevant results. In the next sections, the selected waveforms are shown, with the criteria adopted for the parametric analysis; the developed code is described, and the indexes related to human exposure are defined, according to EN 50444 and EN 50445 (European..., 2008a; 2008b). Further, the main results are presented, and the parameters more relevant to the human exposure are identified and discussed. Final remarks follow.

\section{Methods}

\section{Waveforms}

The three current waveforms used in the analyses are shown in Figure 1: a) trapezoidal, b) exponential and c) combined trapezoidal-exponential ("combined", in the following). Rectangular waveform can be considered as limit case of the trapezoidal one.

There are three parameters, which characterize all the waveforms: peak current $\left(I_{p}\right)$, background current $\left(I_{b}\right)$, and period $(T)$. For the trapezoidal waveform (Figure 1a), $T_{1}$ is the rise time and $T_{2}$ is the fall time. For the exponential waveform (Figure 1b), $T_{3}$ and $T_{4}$ are the rise time constant and the fall time constant
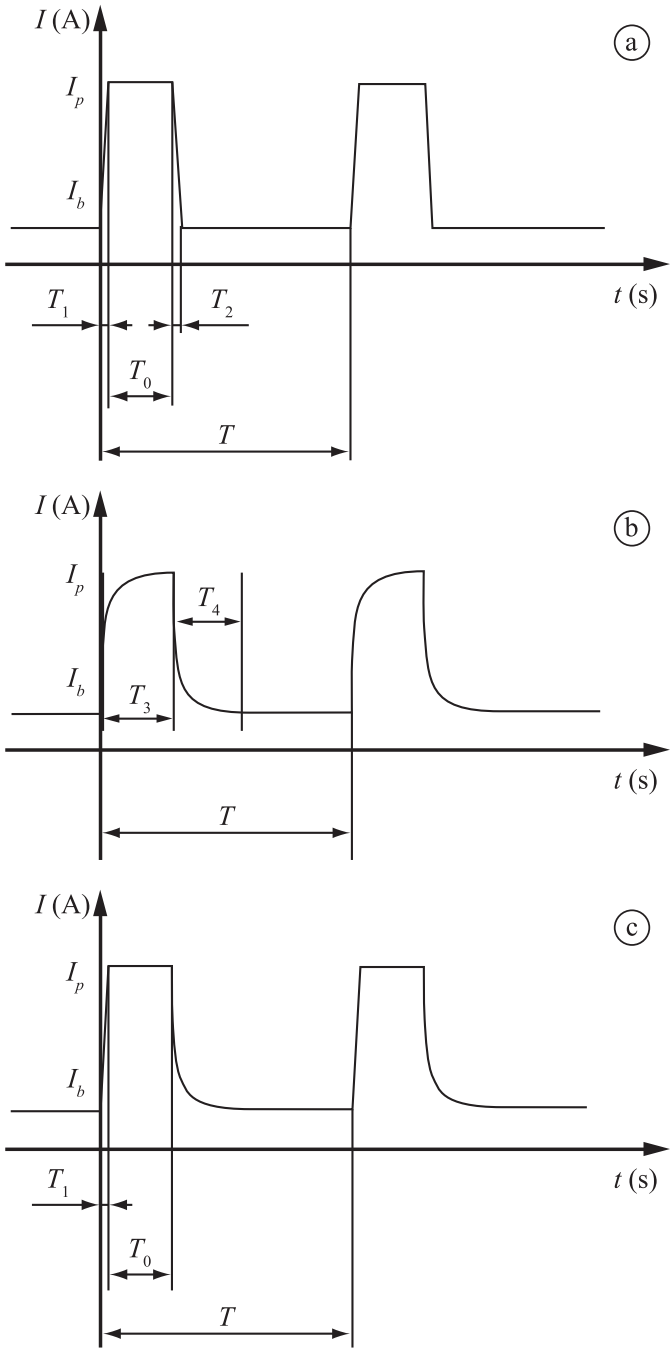

Figure 1. Waveforms used in the analysis: a) trapezoidal, b) exponential, c) combined. 
respectively. Finally, for the combined waveform (Figure 1c), $T_{1}$ is the rise time and $T_{4}$ is the fall time constant.

$T_{0}$ is the peak current duration, clearly recognizable in the cases of trapezoidal and combined in Figure 1a,c. For the exponential waveform, $T_{0}$ is the time interval between $n$ times $T_{3}$ after the rising instant of the current from $I_{b}$ and the starting instant of the fall of the current from $I_{p}$. The choice of $n$ depends on the criteria adopted in the analysis and will be discussed in the following.

\section{Parameters}

One of the research aims in GMAW-P is to get the one droplet per pulse (ODPP) condition (Praveen et al., 2006; Subramanian et al., 1999), where a key parameter is the peak current duration. A typical value of peak current duration is $1 \mathrm{~ms}$, with a frequency $f=1 / \mathrm{T}$ included between 100 and $400 \mathrm{~Hz}$ (Subramanian et al., 1999). Therefore, in this analysis $T_{0}$ has been kept constant and its value was chosen equal to $1 \mathrm{~ms}$.

For sake of simplicity, $T_{1}=T_{2}$ and $T_{3}=T_{4}$ have been taken. Moreover, the criteria of having almost the same value of the current integral on a period for the three waveforms considered (Subramanian et al., 1999) has been used. The integrals of the three waveforms of Figure 1 are:

$A_{1}=I_{p}\left(T_{0}+T_{1}\right)$

$A_{2}=I_{p}\left(T_{0}+n T_{3}+T_{3} \exp \left(-\frac{T_{0}+n T_{3}}{T_{3}}\right)-T_{3} \exp \left(-\frac{\mathrm{T}-\left(T_{0}+n T_{3}\right)}{T_{3}}\right)\right)$

$A_{3}=I_{p}\left(T_{0}+\frac{T_{1}}{2}+T_{3}-T_{3} \exp \left(-\frac{\mathrm{T}-\left(T_{0}+n T_{3}\right)}{T_{3}}\right)\right)$

with $A_{1}, A_{2}$ and $A_{3}$ respectively the area for the trapezoidal, sinusoidal and combined waveforms. In order to have almost the same value of (1), (2), and (3), $T_{3}$ and $n$ have been set equal to $T_{1} / 2$ and 2 respectively, and the exponential terms have been neglected because the inequalities:

$T_{0} \geq T_{1}$ and $\mathrm{T} \geq T_{0}+3 T_{1}$

are fulfilled in the analysis.

For a time-varying analysis, the DC component can be neglected. Therefore for sake of simplicity, the background current has been set to zero (it does not affect the harmonic components).

\section{Numerical code according to EN 50444 and EN 50445}

A new code in MATLAB ${ }^{\circledR}$ has been developed to evaluate the human exposure according to the conditions stated in EN 50444 and EN 50445. This code initially calculates the Fast Fourier Transform (FFT) of the pulsed current waveform under test; the period $\mathrm{T}$ is given as input parameter to the code. From the various current harmonic components, the induced current densities in the human body have been evaluated in the simplest case of a uniform magnetic flux density perpendicular to a homogeneous round disk, with radius $r$ set at $0.2 \mathrm{~m}$. The magnetic flux density, calculated through the Biot-Savart law, has been evaluated at a distance $d=0.2 \mathrm{~m}$ from the conductor. The conductivity $\sigma$ is the one indicated as "body" in EN 50444; as the standard does not foresee a value of $\sigma$ for $f<10 \mathrm{~Hz}$, the minimum frequency of analysis has been set in the code at $10 \mathrm{~Hz}$.

In the analysis only the contribution due to the induced current densities (up to $10 \mathrm{MHz}$ ) has been considered, while the evaluation of SAR has not been performed, because the effects of PWM current ripple have not been taken into account.

The program calculates three different human exposure indexes referred to the induced current. The first one derives from the general multiple frequency rule, that foresees the summation of current density components without phase information. It gives $\alpha_{1}$ :

$$
\alpha_{1}=\sum_{i} \frac{J_{i}}{J_{r e f-i}}
$$

where $J_{i}$ is the RMS value of the $i_{\text {th }}$ frequency component of the induced current density and $J_{\text {ref }-i}$ is the RMS value of the reference value for the current density at the $i_{\text {th }}$ frequency.

The second one includes also phase information and gives $\alpha(t)$ :

$$
\alpha(t)=\left|\sum_{i} \frac{J_{i}}{J_{\text {ref }-i}} \cos \left(2 \pi f_{i} t+\theta_{i}+\phi_{i}\right)\right|
$$

where $\theta_{i}$ is the phase of the $i_{\text {th }}$ component of the current density, and $\varphi_{i}$ is zero for frequencies lower than $1 \mathrm{kHz}$ while is $-\pi / 2$ for frequencies equal or greater to $1 \mathrm{kHz}$ (tabulated values in EN 50445). The maximum of $\alpha(t)$ has been indicated as $\alpha_{2}$.

The third one is obtained by using (6) but with reference levels and phases of the weighting functions for summation of spectral components approximated by a first order filter. In this case, the maximum of $\alpha(t)$ has been indicated as $\alpha_{3}$. 
At least one of the previously defined indexes must not exceed the value of 1 to fulfill the requirements of the standard EN 50444.

\section{Results}

With the numerical analysis, the values of the three indexes $\alpha_{1}, \alpha_{2}$, and $\alpha_{3}$ have been calculated, with a peak current $\left(I_{p}\right)$ set at $100 \mathrm{~A}$.
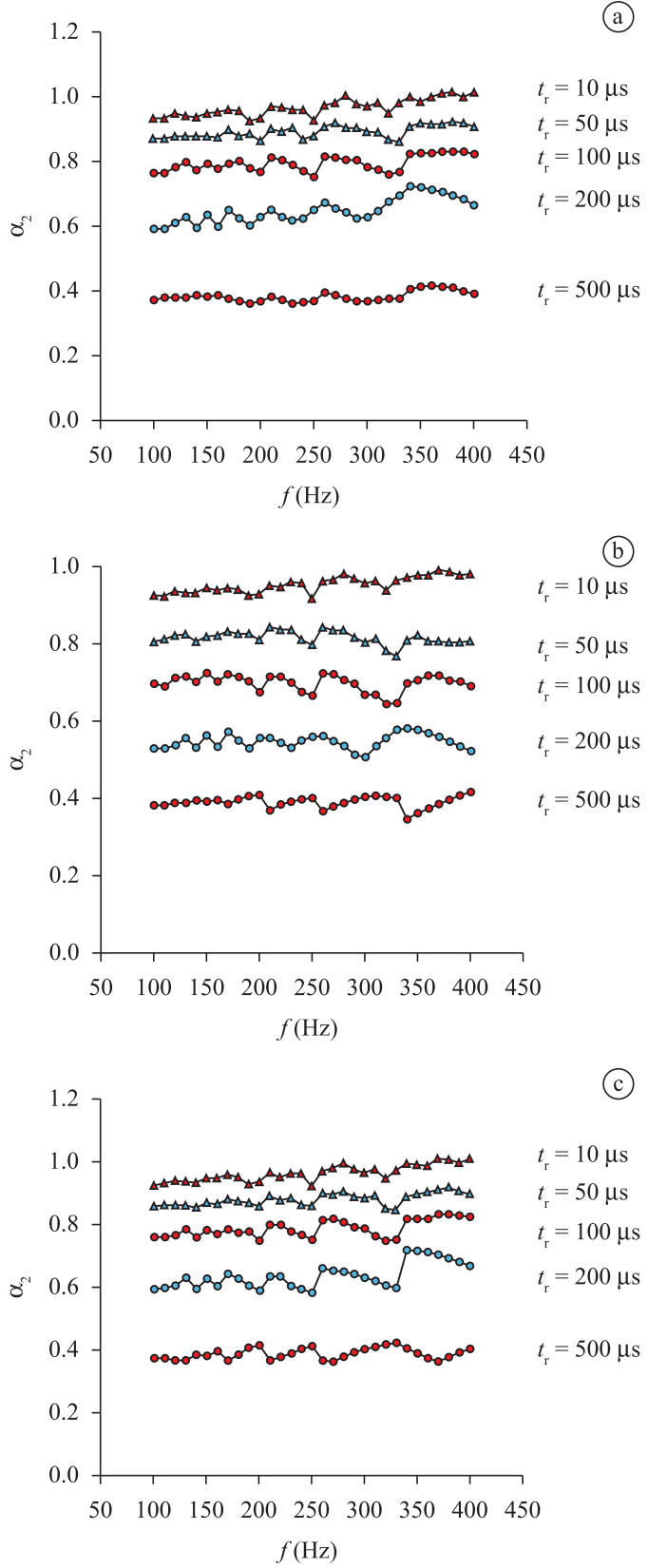

Figure 2. $\alpha_{2}$ versus frequency at different rise time $t_{\mathrm{r}}$ : a) trapezoidal, b) exponential, c) combined.
According to what has been stated above, it has been defined a rise time parameter $t$ which is equal to $T_{1}$ for the trapezoidal and combined waveforms and equal to $2 \cdot T_{3}$ for the exponential one.

Data have been derived by varying continuously the frequency from $100 \mathrm{~Hz}$ up to $400 \mathrm{~Hz}$, with steps of $10 \mathrm{~Hz}$, for five values of $t_{\mathrm{r}}: 10,50,100,200$, and $500 \mu \mathrm{s}$.

A second set of data has been derived by varying continuously $t_{\mathrm{r}}$ from $10 \mu \mathrm{s}$ up to $510 \mu \mathrm{s}$, with steps of $20 \mu \mathrm{s}$, for four values of frequency: 100, 200, 300, and $400 \mathrm{~Hz}$.

As a first result, it has been noticed that when the rise time increases, all the three indexes reduce their values. As an example, in Figure 2a,b,c, $\alpha_{2}$ is given versus frequency at different values of rise time, for the three waveforms shown in Figure 1.

With $t_{\mathrm{r}}$ equal to $500 \mu \mathrm{s}$, a comparison among the three waveforms has been performed, considering the three indexes previously defined. The results are reported in Figure 3. Two remarks can be made from the figure. The behaviour of the waveforms is extremely similar with respect to each index. Moreover, $\alpha_{1}$ gives the highest values, while $\alpha_{3}$ gives the lowest results.

For further comparison, in Figure 4 the data obtained with $t_{\mathrm{r}}$ equal to $100 \mu$ s are shown, organized as in Figure 3. The values of the indexes are higher than before, as expected, but in this case there is not a clear difference between the values of $\alpha_{2}$ and $\alpha_{3}$ : in some cases $\alpha_{3}$ is greater than $\alpha_{2}$.

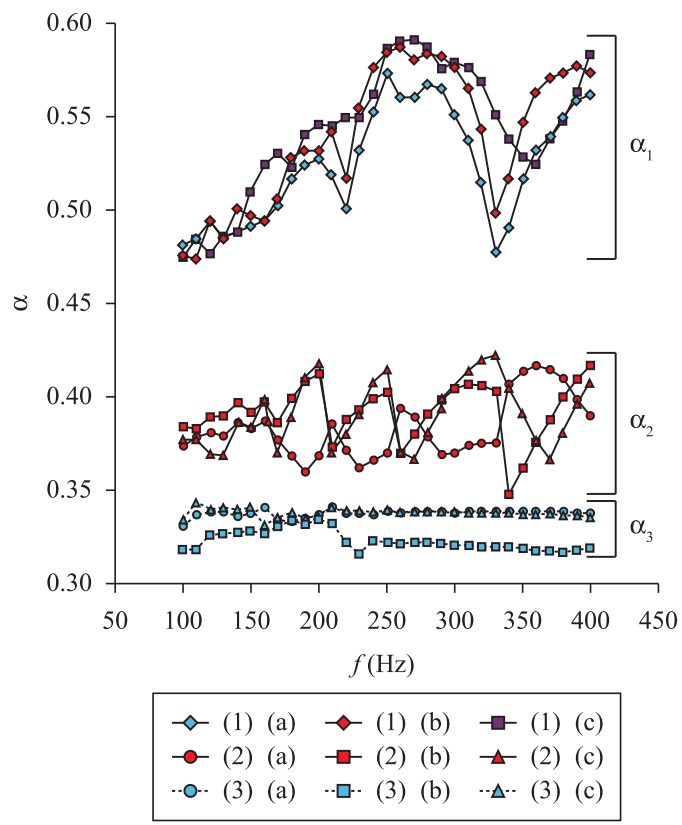

Figure 3. Indexes $\alpha_{1}, \alpha_{2}$, and $\alpha_{3}$ versus frequency at $500 \mu$ s rise time. (1), (2), and (3) correspond to $\alpha$ subscripts; (a), (b), and (c) correspond to trapezoidal, exponential, and combined waveforms. 


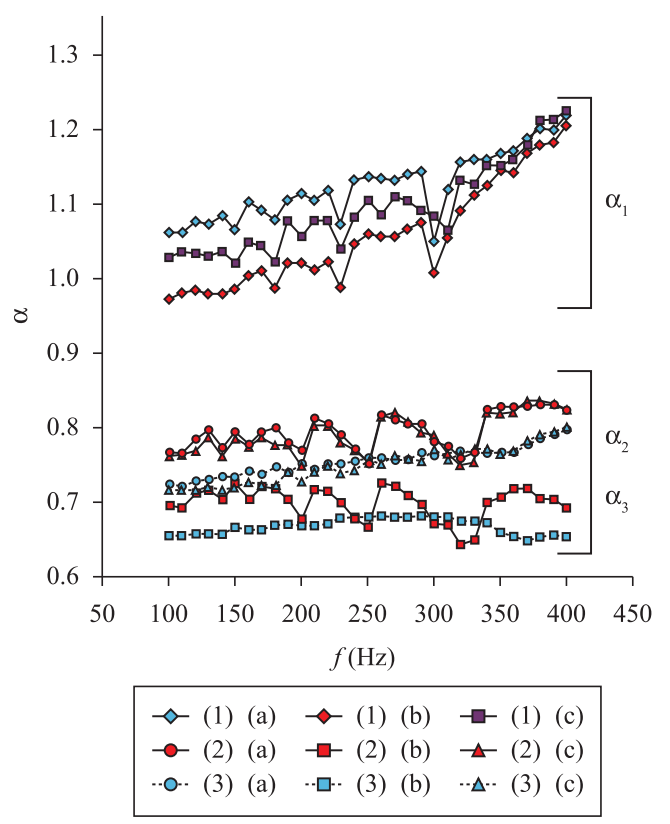

Figure 4. Indexes $\alpha_{1}, \alpha_{2}$, and $\alpha_{3}$ versus frequency at $100 \mu$ s rise time. (1), (2), and (3) correspond to $\alpha$ subscripts; (a), (b), and (c) correspond to trapezoidal, exponential, and combined waveforms.

\section{Conclusion}

The selection of the process parameters in GMAW-P waveform has different effects on welding results. In this work, their difference with respect to human exposure is evaluated. Within the cases analyzed, it has been shown that the main parameter for the reduction of the human exposure indexes is the rise time for all the current waveforms; on the other hand, the effect of the choice of the waveform is much less important.
Finally, as in the ODPP the maximum current can be of several hundreds of amperes, the analysis shows that a proper choice of the rise time is important in the evaluation of the human exposure.

\section{References}

Desideri D, Maschio A. Magnetic field emission up to $400 \mathrm{kHz}$ from a welding equipment. In: International Symposium on Electromagnetic Compatibility: Proceedings oh the 7th International Symposium on Electromagnetic Compatibility, 2006, Barcelona. Barcelona: EMC Europe; 2006. v. 1, p. 151-6.

Desideri D, Maschio A, Mattavelli P. Human exposure to pulsed current waveforms below $100 \mathrm{kHz}$. In: International Symposium on Electromagnetic Compatibility: Proceedings of the 8th International Symposium on Electromagnetic Compatibility, 2008, Hamburg. Hamburg: EMC Europe; 2008. v. 2, p. 57-62.

European Standard. EN 50444: Basic standard for the evaluation of human exposure to electromagnetic fields from equipment for arc welding and allied processes. 2008a.

European Standard. EN 50445: Product family standard to demonstrate compliance of equipment for resistance welding, arc welding and allied processes with basic restrictions related to human exposure to electromagnetic fields (0 Hz - $300 \mathrm{GHz})$. 2008b.

Praveen P, Kang MJ, Yarlagadda PKDV. Arc voltage behavior of one drop per pulse mode in GMAW-P. Journal of Achievements in Materials and Manufacturing Engineering. 2006; 17(1-2):389-92.

Praveen P, Yarlagadda PKDV, Kang MJ. Advancements in pulse gas metal arc welding. Journal of Materials Processing Technology. 2005; 164-165:1113-9.

Subramanian S, White DR, Jones JE, Lyons DW. Experimental approach to selection of pulsing parameters in pulsed GMAW. Welding Research Supplement. 1999; 166-s-72-s.

\footnotetext{
Authors

Daniele Desideri, Alvise Maschio

Department of Electrical Engineering, University of Padova, Via Gradenigo, 6/a, I-35131, Padova, Italy 